\title{
A research-based strategy for inductively accelerating vocabulary acquisition of at-risk students in Grade 4
}

Vitale, Michael R.

East Carolina University, USA (vitalem@ecu.edu)

Romance, Nancy R.

Florida Atlantic University, USA (romance@fau.edu)

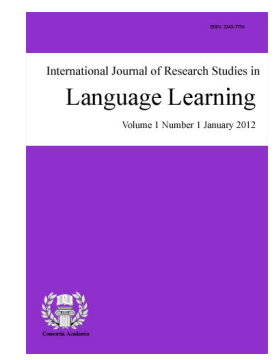

ISSN: $2243-7754$ Online ISSN: 2243-7762

OPEN ACCESS

\section{Abstract}

This study explored the acceleration of vocabulary growth through a multi-part instructional strategy for engendering the inductive, semantic word-family oriented acquisition of vocabulary from context, a difficult task for elementary students. Implemented on a school-wide basis in grade 4 over an 8-week period, the intervention was a four-part enhancement to each of six regular basal reading stories that focused on 17 semantic word families associated with selected words in the stories. Results showed a.) that experimental students inductively generated greater numbers of words with similar meanings that could be substituted for novel words in 3-sentence story-context passages and to word-family pairs; and; b.) that Title 1 experimental students displayed greater achievement than comparable Title I controls on the ITBS Vocabulary Subtest.

Keywords: vocabulary acquisition; vocabulary development; vocabulary strategies; elementary education; instructional strategy 


\section{A research-based strategy for inductively accelerating vocabulary acquisition of at-risk students in Grade 4}

\section{Introduction}

Despite a continuing national emphasis on educational reform over the past 20 years, meaningful learning from text has remained a significant educational problem for many students (e.g., AFT, 1997; Donahue et al., 1999; Feldman, 2000; Snow, 2002), but particularly for low socioeconomic status (SES), at-risk students who depend on school to learn. With regard to correlates of reading comprehension, a variety of research findings has consistently pointed to the interdependent linkage among vocabulary knowledge, reading comprehension, and levels of literacy (e.g., Baker et al., 1998; Becker, 1977; Biemiller \& Slonim, 2001; Snow, 2002; Wagner, 2005). Although many researchers have emphasized that a substantial amount of vocabulary growth can be attributed to student acquisition of word meaning from reading contexts (Baker et al., 1998), Landauer and Dumas (1997) noted that indirect learning of vocabulary from reading context assumes a rate of learning new words that is unrealistic, despite the extensive amount of reading in which students engage in school settings.

As noted above, research findings have consistently pointed to the linkage among vocabulary knowledge, reading comprehension, and levels of literacy (e.g., Baker et al., 1998; Becker, 1977; Biemiller \& Slonim, 2001; Wagner, 2005). These consensus research findings found that low-SES, at-risk students lag behind their more advantaged peers in both vocabulary development and in reading comprehension. Although a substantial amount of vocabulary growth can be attributed to indirect learning of word meaning from reading contexts (Baker et al., 1998), August et al. (2005) noted that if the proportion of unknown words is too large, then text comprehension which serves as a context for vocabulary development is disrupted (see also Carver, 1994). In this regard, Wagner (2005) showed that the development of vocabulary and reading comprehension are highly interdependent.

Some time ago, Becker (1977) pointed to the fact that even though at-risk students could become fluent readers at the primary (K-3) levels, substantial deficiencies in their vocabulary knowledge formed a significant barrier to their future academic success in subsequent grade levels. At the same time, because students with poor vocabularies do not acquire new words as rapidly as students with rich vocabularies (Boucher, 1986), the vocabulary gap between at-risk and advantaged students widens throughout school. In this regard, Beck and McKeown (1991) reported that high achieving seniors had four times the vocabulary as low achieving seniors and, more importantly, that the vocabularies of low achieving seniors were equal only to that of higher achieving third graders.

Ignoring technical details of how words (e.g., counting word roots vs. root variants) and word understanding (e.g., recognition vs. in depth understanding) are defined in the literature (e.g., Anglin, 1993; Beck \& McKeown, 1991), research findings are in agreement that children acquire vocabulary at a rate that is far too rapid for all the words to be taught directly (see Baker et al., 1998). Although an increasing numbers of studies have identified factors important in teaching vocabulary in classroom settings (see Baker et al., 1998; Coyne et al., 2005; Nagy \& Scott, 2000), such studies have limitations insofar as providing a comprehensive means for accelerating student vocabulary acquisition. For example, Baker et al. (1998) pointed to the fact that the size and rate of growth of the vocabulary of school age children is far too large to be addressed on a literal word-by-word basis alone, while Anderson \& Nagy (1992) argued that because word meaning is learned primarily in the context of speech or text, direct instruction of vocabulary can address only a small portion of words to be learned.

The present study approached the question of vocabulary acquisition from a knowledge-based instruction approach (see Bransford et al., 2000; Luger, 2008). A major tenet of this perspective is that prior knowledge is a major factor in meaningful comprehension, learning, and expert performance. Within this framework, building 
A research-based strategy for inductively accelerating vocabulary acquisition of at-risk students

prior knowledge has been recognized as a major determinant of meaningful learning, general comprehension, and reading comprehension. In applying a knowledge-based perspective to the classical problem of how persons can know more than experience could have taught (literally) within the context of vocabulary, Landauer (2002) and Landauer and Dumas $(1997,1998)$ drew on the idea that the underlying semantic dimensions that represent the relatedness among words, phrases, and prose provide the "learning leverage" through which words are understood. From this perspective, both the traditional and cognitive science research literatures are consistent in that while vocabulary words can be taught directly, the majority of vocabulary must be gained in a fashion that is inferential. Although some indirect vocabulary acquisition can be explained through reading, the rate of vocabulary acquisition exhibited by children requires a process that involves the induction of the meaning of new words (since direct teaching and incidental learning from reading contexts are inadequate to explain vocabulary growth).

The specific problem addressed was whether student vocabulary acquisition could be accelerated by using a multi-part, semantic-oriented learning strategy to inductively broaden vocabulary taught directly. In incorporating criteria suggested by Baker et al. (1998) and Beck and McKeown (1991), the intent of the multi-part strategy used was: a.) to develop a deep understanding of vocabulary words taught in a time-efficient fashion; b.) to engender an inductive broadening of the vocabulary taught directly through semantic-based (indirect) learning; and c.) to be feasible for use by classroom teachers within regular classroom settings with minimal training and support. Implemented as a practitioner-oriented model, the instructional intervention reflected several inter-disciplinary perspectives: a.) vocabulary research findings with both younger (e.g., Coyne et al., 2005) and older (e.g., August et al., 2005; Baker et al., 1998; Blachowicz \& Fisher, 2000; Johnson et al., 1987) students; b.) cognitive science models (e.g., Kintsch, 2002, 2004, 2005; Landauer, 2002; Landauer, \& Dumais, 1996, 1997; Landauer et al., 1998) that emphasize the central role of prior knowledge in comprehension; and c.) our research (Vitale \& Romance, 2007) investigating the effect of knowledge-focused reading comprehension strategies on student learning. In the present study, different aspects of these perspectives provided a framework for engendering the semantically-oriented inductive learning of vocabulary.

The specific research questions were as follows:

1. Did the multi-part instructional intervention which incorporated words taught directly and indirectly serve to accelerate the vocabulary development as measured by curriculum-based transfer tests?

2. Did the multi-part instructional intervention engender a transfer effect to vocabulary performance as measured by a nationally-normed standardized test?

3. Was the multi-part intervention differentially effective with at-risk students (defined by low-SES/Title I status)?

\section{Methodology}

\subsection{Participants}

The study was implemented on a school-wide basis in grade 4 in four demographically-representative elementary schools in a large (185,000 students), highly diverse (African American: 29\%, Hispanic: 19\%, Other: 5\%, Free Lunch: $40 \%$ ) school system in southeastern Florida. Using a random selection process with constraints, two of the four schools were assigned to the intervention and two served as controls (see following section for details).

\subsection{Instrumentation}

The study used two different forms of instrumentation, one that focused on study-specific (i.e., curricular) vocabulary acquisition and one that focused on general outcome measures. In the first form, a 
researcher-developed Vocabulary Thinking Test (VTT) was used to assess (a) student in-depth understanding of words taught indirectly within a basal reading context and (b) student capacity to understand and intellectually access words having semantic similarity to those taught in the intervention. However, unlike vocabulary tests that focus on word definitions, the VTT required students to respond to text-word scenarios by generating sets of words having similar meanings appropriate to the context presented by following the form of inductive process suggested by Landauer (2002).

The curriculum-based VTT test consisted of three parts which used different item formats. In Format 1, students were asked to generate up to four words which could replace a novel designated word (i.e., a word from the semantic family not used in instruction) appearing within three-sentence "blocks" extracted from a basal text story (these three-sentence blocks were previously used for direct and indirect vocabulary instruction - see following section). In Format 2, students were asked to generate up to six words whose semantic meaning was similar to a pair of words that was taught inductively (i.e., only through content-oriented substitution) in instruction. In Format 3, students were asked to generate up to four words that would be appropriate to fit in a blank appearing within three-sentence blocks extracted from the basal text story. In all cases different 3-sentence blocks from the stories were used in Format 1 and Format 3. In all cases, the word-pairs used in Format 2 referenced (contextually) did not appear in the different 3 -sentence blocks used in Format 1 and Format 3. Thus, the words used in the test were either taught indirectly (Format 2) or not taught at all, i.e., words used in Format 3 were novel members of the same semantic families used in instruction.

Each of the three parts of the VTT test consisted of six items and each part of the test was scored separately, with scores expressed as the percentage of correct responses per part (i.e., the number correct relative to the total number of possible correct responses in a particular part). Tests were hand-scored in a classroom-randomized order by research assistants who had completed a brief training sequence and applied a common scoring template. Scoring reliability represented as the percent of agreement obtained at intervals as the tests were scored showed a consistently high degree of agreement throughout the scoring process (i.e., average differences in commonly scored marker tests were less than 2 points).

The general outcome measure consisted of the nationally-normed Iowa Tests of Basic Skills (ITBS) Vocabulary subtest. The ITBS is a nationally-normed standardized test battery used in U.S. schools. In addition, the state-administered Florida Comprehensive Assessment -Stanford Achievement Test (FCAT-SAT) Reading Comprehension subtest, administered prior to the start of the study was used as a covariate. The FCAT-SAT is an adaptation of the nationally-normed Stanford Achievement Test administered statewide for school accountability.

\subsection{Vocabulary Instruction Intervention}

In developing the instructional strategy used, researchers first identified six basal reading stories that were to be used in the four schools during the study. Because the District had a common basal reading adoption, all participating experimental and control schools used the same basal stories. Next, for each of the six common stories selected, the researchers selected three key vocabulary words embedded within the story text for each lesson (with the exception that only two key words were selected for one of the stories). The selected key words formed the framework for the experimental treatment. In turn, for each key word selected, researchers then identified six additional (target) words having similar meaning using a computer-based word-processing thesaurus (e.g. Word) complemented by "WordNet," a software tool accessible through the Internet. In the experimental treatment, one pair of these additional words was randomly selected to be taught directly, a second pair of the additional words was taught inductively in context, and the remaining pair of words was withheld for possible use in test item formats.

The classroom intervention was a four-part enhancement to each of the six regular basal reading stories in grade 4 and focused on 17 semantic word families (i.e., one word family for each key word). In Part 1, teachers followed the regular (direct) vocabulary instruction procedures specified by their basal texts; including 
A research-based strategy for inductively accelerating vocabulary acquisition of at-risk students

pre-teaching the three key vocabulary words in the story and using a definitional paraphrase to specify the meaning of each. Teachers then followed the regular basal text procedure in which students read the story, with the exception that as students read, the teacher stopped and reviewed the definition of each key vocabulary word with the students after the sentence in which it is embedded was read (e.g., What does the word mean in this sentence? How does this word contribute to the overall meaning of this sentence?).

In Part 2, after the regular reading portion of the weekly session was completed, teachers introduced students to new experimental target words (one pair for each of the three key words), following a direct pre-teaching procedure similar to that used for the key words (i.e., paraphrase definition, linking the target word to the key word). Then, for each target vocabulary word, teachers selected a student to re-read three sentences in the reading passage: (a) the sentence with the original vocabulary key vocabulary word and (b) two other sentences, one immediately preceding and one immediately following the sentence with the original key vocabulary word. The additional sentences selected were chosen to contribute as meaningfully as possible to the context for the sentence with the original key vocabulary word. Teachers then selected a new student reader and repeated the same procedure, but with the student substituting the new target word for the original key word. As part of the three-part sentence re-reading process, the teacher again asked the questions: What does the word mean in this sentence? How does this word contribute to the overall meaning of this sentence? and an additional question: How does the use of this new word change the meaning of the sentence or story?

In Part 3, teachers wrote two new words on the board for each key word, but rather than pre-teaching, only used the 3-sentence substitution procedure as a the means of establishing the meaning of the new words in context (i.e., rather than direct pre-teaching, students substituted each new target word for a key word as part of the three-sentence re-reading process and determined their meaning inferentially.) Again, teachers again asked the questions: What does the word __ mean in this sentence? How does this word contribute to the overall meaning of this sentence? and added additional question: How did the meaning of the three sentences from the story suggest what the meaning of the new word should be?

Finally, in Part 4, teachers wrote all key and target words on the board in a random order and asked students to generate their own sentences that told something they experienced using the original key or target words (i.e., each selected student generated one new sentence with a specified word). In the vocabulary expansion task (Part 4), teachers accepted both key words and target words that were directly taught as well as the additional target words learned inductively in context. Depending upon the pace of weekly lessons, teachers devoted approximately 15 minutes per day, 2 days per week to the vocabulary strategy. In the present study, having students engaged in a meaningful task in which they relate new words to an underlying semantic foundation (i.e., context) is highly relevant to the process of vocabulary induction outlined by Landauer (2002).

\subsection{Design and Procedure}

The overall design goal was to identify two pairs of demographically similar schools who would volunteer to participate (if selected) and then randomly assign one member of each pair to the experimental or control condition. This process was implemented by randomly choosing each member of a pair and asking each to participate (which each did) and then using the other member of the pair as a control. The multi-part instructional intervention was implemented on a school-wide basis with all grade 4 teachers over an 8-week time period during the Spring semester of the school year after the state-administered FCAT prior to the beginning of the study. Table 1 shows the demographic characteristics of the four schools.

The original design of the study called for all student achievement data to be obtained at the end of the school year. However, because of school-based concerns of over-testing, the administration of the curriculum-based VTT vocabulary tests and the ITBS Vocabulary subtest was delayed until the start of the following school year, after the students had become fifth graders. As a result, the study-developed curriculum-based test and the ITBS Vocabulary subtest provided measures of the long-term impact of the 
Vitale, M. R. \& Romance, N. R.

intervention on students' subsequent performance in grade 5 (the 8-week intervention terminated at the end of grade 4 in the preceding year.) All tests were administered at the classroom level by regular classroom teachers.

Table 1

Demographic Characteristics of Participating Schools in Grade 4

\begin{tabular}{cccccc}
\hline $\begin{array}{c}\text { Participating } \\
\text { Schools }\end{array}$ & $\begin{array}{c}\text { N } \\
\text { Teachers }\end{array}$ & $\begin{array}{c}\text { Participants } \\
\text { Title 1 }\end{array}$ & $\begin{array}{c}\text { Participants } \\
\text { White }\end{array}$ & $\begin{array}{c}\text { Participants } \\
\text { Black }\end{array}$ & $\begin{array}{c}\text { Participants } \\
\text { Hispanic }\end{array}$ \\
\hline $\begin{array}{c}\text { Experimental } \\
\text { School A }\end{array}$ & 7 & 16 & 82 & 3 & 10 \\
School B & 4 & 45 & 49 & 33 & 9 \\
Control & & & & & 7 \\
School C & 6 & 66 & 36 & 34 & 22 \\
School D & 3 & & & & \\
\hline
\end{tabular}

Teacher training consisted of 2 days prior the start of the intervention. In addition, two days were used for "follow-up" support. The primary focus of all professional development was on (a) insuring teachers had a sound understanding of the instructional strategies and student activities they were to use, and (b) that they understood how to incorporate the additional words identified each week in their reading lessons. Researchers informally monitored grade 4 classrooms in both participating schools on a regular basis. In addition to clinical fidelity observations, teachers maintained weekly lesson plans for inspection that showed the activities conducted for each lesson (i.e., use of the multi-part vocabulary expansion strategy).

Statistical analysis of the study findings followed a 2 × 2 (Factor 1: Treatment vs. Control, Factor 2: Title 1 (Free/Reduced Lunch vs. non-Title 1) ANCOVA, with prior FCAT-SAT Reading Comprehension administered prior to the beginning of the study serving as a covariate. The two sets of outcome measures were analyzed separately. First, the 3 parts of the study-developed curriculum-based VTT vocabulary test were analyzed using multivariate covariance analysis. Second, the ITBS Vocabulary subtest was analyzed using univariate covariance analysis. In building the statistical analysis models, the main effects were fit first and then, the additional contribution of the interaction components were determined. If the interaction component was not significant, then it was not added to the final analysis model.

\section{Results}

\subsection{Descriptive Statistics}

Table 2 shows the descriptive statistics for participating schools in the study. In inspecting Table 2, it should be noted that the specific number of students included in the following analyses varied to a small degree because of missing data.

Table 2

Means and Standard Deviations of Grade 4 Students in Participating Schools

\begin{tabular}{|c|c|c|c|c|c|c|c|c|c|c|c|c|}
\hline \multirow{2}{*}{$\begin{array}{c}\text { Participating } \\
\text { Schools }\end{array}$} & \multirow{2}{*}{$\begin{array}{c}\mathrm{N} \\
\text { Stud. }\end{array}$} & \multirow{2}{*}{$\begin{array}{c}\mathrm{N} \\
\text { Tch }\end{array}$} & \multicolumn{2}{|c|}{ SAT-RD } & \multicolumn{2}{|c|}{ VTT-F1 } & \multicolumn{2}{|c|}{ VTT-F2 } & \multicolumn{2}{|c|}{ VTT-F3 } & \multicolumn{2}{|c|}{ ITBS VOC. } \\
\hline & & & $M$ & $S D$ & $M$ & $S D$ & $M$ & $S D$ & $M$ & $S D$ & $M$ & $S D$ \\
\hline \multicolumn{13}{|l|}{ Experimental } \\
\hline School A & 120 & 7 & 673 & 34 & 38 & 17 & 23 & 12 & 23 & 16 & 6.7 & 1.2 \\
\hline School B & 73 & 4 & 662 & 43 & 34 & 21 & 18 & 10 & 19 & 15 & 6.7 & 1.6 \\
\hline \multicolumn{13}{|l|}{ Control } \\
\hline School C & 96 & 6 & 665 & 34 & 31 & 15 & 16 & 9 & 17 & 14 & 6.5 & 1.2 \\
\hline School D & 41 & 3 & 649 & 37 & 19 & 16 & 14 & 10 & 14 & 13 & 5.5 & 1.7 \\
\hline
\end{tabular}

Note. $\mathrm{N}$ Stud. = Number of grade 5 students for which the preceding years grade 4 FCAT-SAT reading scores were available for analyses, $S A T-R D=F C A T-S A T$ Stanford Achievement Test Reading subtest scale scores used as a covariate in the analyses, VTT $=$ the percent of correct items for the study-developed Vocabulary Thinking Test (Formats 123 ), ITBS VOC = the grade equivalent scores for the Iowa Tests of Basic Skills Vocabulary subtest. 


\subsection{Analysis of Achievement Outcomes}

As noted in the preceding section, separate analyses were conducted on the three-part, study-developed VTT and the ITBS Vocabulary subtest.

\subsubsection{VTT achievement findings}

Table 3 summarizes the results of the multivariate ANCOVA analysis conducted on the three-part VTT. As Table 3 shows, the effect of the vocabulary intervention was significant for each of the three parts of the VTT, indicating that students receiving the experimental treatment were more successful in being able to produce words whose semantic meanings were appropriate for the variety of text-based contexts comprising the tests. Non-Title 1 students scored significantly higher than Title 1 students on each of the parts of the VTT. However, because the interaction between the two main effects was not significant, the findings showed that the effect of the experimental treatment was consistent (vs. comparable controls) for both low-SES (Title 1) students and their more advantaged non-Title 1 peers. In interpreting the preceding findings, it should be noted that all of the effects were conditional (i.e., compared adjusted means) on the FCAT-SAT reading subtest that was used as a covariate (which was significantly related to student VTT achievement).

\section{Table 3}

Results of Multivariate Covariance Analysis of Achievement Outcomes for the Study-Developed Vocabulary Thinking Test (VTT)

\begin{tabular}{|c|c|c|c|c|}
\hline $\begin{array}{c}\text { Statistical } \\
\text { Model Component }\end{array}$ & $\begin{array}{c}\text { Multivariate } \\
F \text { Approx. }(d f)\end{array}$ & $\begin{array}{c}\text { VTT- Format } 1 \\
F(d f) \\
\end{array}$ & $\begin{array}{c}\text { VTT-Format } 2 \\
F(d f)\end{array}$ & $\begin{array}{c}\text { VTT-Format } 3 \\
F(d f)\end{array}$ \\
\hline \multicolumn{5}{|l|}{ Main effects } \\
\hline Exp. Treatment & $\mathrm{F}(3,337)=8.71 * *$ & $\mathrm{~F}(1,339)=14.86^{* *}$ & $\mathrm{~F}(1,339)=17.27 * *$ & $\mathrm{~F}(1,339)=5.79 *$ \\
\hline Title 1 & $\mathrm{~F}(3,337)=6.52 * *$ & $\mathrm{~F}(1,339)=6.76^{*}$ & $\mathrm{~F}(1,339)=14.74 * *$ & $\mathrm{~F}(1,339)=6.80 *$ \\
\hline Pre-Test Covariate & & & & \\
\hline SAT-Reading & $\mathrm{F}(3,337)=29.52 * *$ & $\mathrm{~F}(1,339)=57.51 * *$ & $\mathrm{~F}(1,339)=30.02 * *$ & $\mathrm{~F}(1,339)=39.59 * *$ \\
\hline
\end{tabular}

\subsubsection{ITBS achievement findings}

Table 4 summarizes the results of the ANCOVA conducted on the ITBS Vocabulary subtest. As Table 4 shows, the effect of the vocabulary intervention was significant, indicating that students receiving the experimental treatment obtained higher grade-equivalent scores on ITBS Vocabulary after statistically equating students on prior FCAT-SAT Reading achievement (adj. mean difference = .32 GE). As was the case with the $V T T$, non-Title 1 students displayed significantly higher vocabulary proficiency than Title 1 students (adj. mean difference $=.57 \mathrm{GE}$ ). However, unlike the findings for the VTT, the interaction between the two main effects was significant, indicating that the effect of the experimental treatment differed for Title 1 vs. non-Title 1 students. Follow-up simple effects analysis showed that for Title 1 students, the adjusted means difference (.7 GE in favor of the experimental group) was statistically significant, $F(1,323)=7.67, p<.001$, while for non-Title 1 students, the adjusted means difference between experimental and control students (approximately zero -.005 GE), $F(1,323)=.001$, NS. Thus, the experimental intervention had the effect of improving ITBS Vocabulary achievement of Title 1 students (vs. Title 1 controls). It also should be noted that all of the effects were conditional (i.e., compared adjusted means) on the FCAT-SAT reading subtest that was used as a covariate (which was significantly related to student ITBS Vocabulary achievement).

\section{Discussion}

The results are supportive of the validity of the multi-part instructional strategy for accelerating student vocabulary development. Adding to the impact of the findings is that student performance on the VTT paralleled 
Vitale, M. R. \& Romance, N. R.

aspects of the reading comprehension process itself in which students were required to utilize context in reading as a basis for inducing comprehension for words (or concepts) that are not completely known. The generative tasks comprising the VTT provided a controlled assessment of the development of this proficiency. In addition, the fact that the experimental intervention also had a significant overall impact on the vocabulary proficiency of Title I (low SES) at-risk students as measured by the nationally-normed ITBS Vocabulary subtest is suggestive of a potential transfer effect for differentially accelerating general vocabulary growth of such at-risk students.

\section{Table 4}

Results of Analysis of Achievement Outcomes for the ITBS Vocabulary Subtest

\begin{tabular}{ll}
\hline \multicolumn{1}{c}{ Statistical Model Component } & ITBS VOC $F(d f)$ \\
\hline $\begin{array}{l}\text { Main effects } \\
\text { Exp. Treatment } \\
\text { Title 1 }\end{array}$ & $\mathrm{F}(1,323)=5.27 *$ \\
$\begin{array}{l}\text { Interaction } \\
\text { Exp. Treatment X Title 1 }\end{array}$ & $\mathrm{F}(1,323)=14.54^{* *}$ \\
$\begin{array}{l}\text { Covariate } \\
\text { SAT Reading }\end{array}$ & $\mathrm{F}(1,323)=5.48^{*}$ \\
\hline Note. $* p<.05, \quad * * p<.01$. & $\mathrm{F}(1,323)=124.90 * *$ \\
\hline
\end{tabular}

\subsection{Linkage between Vocabulary and Reading Comprehension}

As noted previously, a variety of research findings have consistently pointed to the interdependent linkage among vocabulary knowledge, reading comprehension, and level of literacy (e.g., Baker et al., 1998; Becker, 1977; Biemiller \& Slonim, 2001; Wagner, 2005). Also, as Becker (1977) pointed out, the substantial deficiencies in vocabulary knowledge form a significant barrier to their future academic success in following grade levels while the vocabulary gap between at-risk and advantaged students widens throughout school (Boucher, 1986). In this regard, Beck and McKeown (1991) reported that high achieving seniors had four times the vocabulary as low achieving seniors and, more importantly, that the vocabularies of low achieving seniors were equal only to that of higher achieving third graders.

\subsection{Traditional Perspectives on Vocabulary Growth}

Consensus research findings are in agreement that children acquire vocabulary at a rate that is far too rapid for all the words to literally be taught directly (see Baker et al., 1998). For example, Beimiller and Slonim (2001) normatively estimated that children knew 5,200 root words (i.e., word families) by grade 2 and 8,400 root words by grade 5, estimates similar to those reported by Anglin (1993). However, using root words as a foundation, expanded estimates by Anglin (1993) of the total number of words known by grade 2 and grade 5 students were 10,000 and 40,000, respectively. In addition, Beimiller and Slonim (2001) reported that by grade 2, children with high vocabularies know 4000 more root words than children experiencing delays in vocabulary development. In a complementary study, Nagy and Anderson (1984) found that educational English materials used in grades 3 through 9 required students to have gained an understanding of approximately 88,000 word families. As definitions of vocabulary growth have become more refined and consistent, reviews of vocabulary research suggest that the number of new words (vs. root words) at the elementary levels is about 3,000 per year (Bauman \& Kameenui, 1991; Beck \& McKeown, 1991; Graves, 1986) or approximately 8 words per day.

In addressing the question of vocabulary acquisition, researchers (Hart \& Risley, 1995; National Research Council, 1998) have pointed to the fact that there are extensive differences between the degree of oral language experiences among children prior to their beginning school with corresponding differences in their vocabularies (see also Beimiller \& Slonim, 2001). For example, in an extensive literature review, Graves (1986) reported that the differences in the reading vocabularies of middle class vs. low-SES children in grade 1 were 2,700 and 1,800 words, respectively, of a reference domain of 5,044 words. Using a larger domain of words $(19,050)$, Graves also 
A research-based strategy for inductively accelerating vocabulary acquisition of at-risk students

reported research findings that low SES grade 1 students knew 2,900 words in comparison to middle class students who knew 5,800 words. As Baker et al. (1998) reported, vocabulary growth differences between students not only are apparent prior to and during the school years; but also the gap in vocabulary knowledge widens rapidly as grade level increases. In this regard, Beck and McKeown (1991) noted extensive differences in rates of student word acquisition. More specifically, in an investigation of students who began school with poor vocabularies, White et al. (1990) found that vocabulary differences between students in a middle SES school and two low SES schools were 1,300 and 2,300 words, respectively. However, by grade 3 these differences between the middle SES and low SES schools had grown to 5,000 words. Thus, the magnitude of what is a cumulative deficiency in vocabulary growth by low-SES at-risk students is a significant barrier to overcome.

An increasing number of studies have demonstrated that vocabulary words can be taught effectively in classroom settings (see Baker et al., 1998; Coyne et al., 2005; Nagy \& Scott, 2000). As experimental demonstrations, these studies have identified factors important in teaching vocabulary (these are discussed in a following section). However, at the same time, such studies have a number of limitations insofar as providing a means for accelerating student vocabulary acquisition. First, a number of researchers (e.g., Baker et al., 1998) have pointed to the fact that the size and rate of growth of the vocabulary of school age children is far too large to be addressed on a literal word-by-word basis alone. In this regard, Stahl and Sheil (1999) noted that with present approaches, teaching students 300-400 new word meanings per year is a realistic and valuable expectation (i.e., for vocabulary weak students who would normally learn only 1,000 words per year, learning an additional 300 words would be a $30 \%$ improvement). While such an initiative could help to provide a vocabulary foundation for at-risk students, it falls far short of providing a systemic curricular solution. As a parallel concern, teaching new vocabulary to a level of in-depth understanding typically requires extensive practice in the form of repeated exposures (see Nagy \& Scott, 2000) which, in turn, requires extensive amounts of instructional time per learned word. For example, in a study by Beck et al. (1982) students learned an average of 85 of 104 words taught in 7530 -minute lessons for a total time of 2,250 minutes or 26 minutes per word learned. At the same time, while Johnson et al. (1987) showed that the amount of learning time per word can be reduced to some degree by using instruction emphasizing small sets of words to be learned at one time in conjunction with spaced cumulative review, teaching vocabulary on a word by word basis is highly time intensive.

The second limitation of literally teaching words directly follows from the argument that the majority of new vocabulary words are learned contextually through reading. For example, Anderson \& Nagy (1992) have argued that because word meaning is learned primarily in the context of speech or text, direct instruction of vocabulary can address only a small portion of words to be learned. Thus, while direct school instruction could be used to provide students with a limited core of vocabulary knowledge as a foundation for enhancing academic growth (Paul \& O'Rourke, 1988), the scope of vocabulary learned directly is far less than that gained through indirect means. At the same time, indirect approaches that would address vocabulary acquisition through reading also present problems. As noted previously, students who are weak in vocabulary are also likely to be weak in reading (see Wagner, 2005). Thus, such students are unlikely to be able to use comprehension of context in reading as a strategy for learning new words. In addition, as Landauer and Dumas (1997) noted, indirect learning of vocabulary from reading context still assumes a rate of learning new words that is unrealistic and which is at most, $1 / 6$ of the natural rate of acquisition, despite the extensive amount of reading students engage in within school settings.

The third limitation of literally teaching words directly is that presently there is no recognized curricular structure or standards for a developmental vocabulary curriculum (see Biemiller \& Boote, 2006). In this regard, some representative initial efforts can be noted. Biemiller and Slonim (2001) have identified a developmental sequence in which root vocabulary words are learned at the elementary levels. Johnson and Johnson (2004) have developed an articulated vocabulary development program for students in grades 3-12. Zeno et al. (1995) have compiled a word frequency database for use by educators. However, keeping in mind the findings of Anglin (1993) in which he reported substantial differences in knowledge between root words and derived words (e.g., word inflections), there is a significant need for a systemic national initiative to address the issue of 
developmental vocabulary curriculum that would be organized around core morphemic elements and an associated teaching methodology that would engender the inductive processes that students must logically use in order to accomplish a greater rate of vocabulary learning than direct experience with words can explain.

\subsection{Cognitive Science Perspectives on Vocabulary Acquisition}

The strategy employed in the present study was to consider the question of vocabulary acquisition from a knowledge-based instruction approach (see Bransford et al., 2000; Luger, 2004). A major tenet of this perspective is that prior knowledge is a major factor in meaningful comprehension, learning, and expert performance. Within this framework, as Bransford et al. have noted, in comparison to novices, experts are able to organize and access knowledge in a fashion that allows them to apply it to problems through automaticity. In this regard, building prior knowledge has been recognized as a major determinant of meaningful learning, general comprehension, and reading comprehension in particular.

As an example, the construction-integration model developed by Kintsch and his colleagues (e.g., Kintsch, 1994, 1998a, 1998b, 1998, 2002, 2005) has been applied extensively to the question of reading comprehension. As an informal overview, Kintsch's model explains the process of reading comprehension by distinguishing between the propositional structure (i.e., semantic meaning cohesiveness) of a text that is being read and the prior knowledge the reader brings to the process of reading. Within this context, meaningful comprehension results when the prior knowledge of the learner is able to join with the propositional structure of the text. If the propositional structure of the text is highly cohesive (i.e., knowledge is explicitly well-represented in propositional form), then there is less demand upon reader prior knowledge. But if the text is not cohesive (i.e., contains significant semantic gaps), then reader prior knowledge is critical for understanding. In either case, comprehension results from the integration of the propositional structure of the text (textbase) with the readers prior knowledge and is represented semantically in propositional form (a situation model). Within this framework, much of the research conducted by Kintsch and his colleagues has focused on the interplay of meaningful text structure and the prior knowledge of the reader considered as a learner.

Although Kintsch (1998a, 1998b) has not explored the question of vocabulary learning per se within the scope of his model, some his colleagues have done so. In particular, Landauer (2002) along with others (Landauer \& Dumas, 1996, 1997; Landauer et al., 1998) has addressed the major limitations associated with traditional perspectives of vocabulary acquisition presented in earlier sections. Briefly, their research-based arguments emphasize that learning vocabulary is primarily an inductive process that is based upon the utilization of the prior knowledge that is derived from the experience of the learner. As a focus of their research, Landauer et al. (1998) have developed a computational model through which the relatedness of words to words, words to prose, and prose to prose can be expressed mathematically via an index ranging from 1 to -1 across a large number of underlying semantic dimensions. In effect, Landauer and his colleagues have been able to show that the "gist" of the meaning of a passage is measurable as a sum of its composite words and, in turn, that the meaning of individual words can be measured in terms of its relationship to other words (think informally of the meaning of a word as a "bag" of words, i.e., a group of semantically related words consisting of synonyms and anonyms to which it is related via a set of fundamental underlying dimensions).

In the application of his model- Latent Semantic Analysis (LSA) - Landauer has been able to demonstrate very convincing correspondences between the relationships among words, phrases, and/or passages that are highly consistent with human judgments, including using the LSA model to obtain average performance on a nationally-normed vocabulary test. And, of even greater importance, the LSA model is able to show that words and passages are similar even though they share no immediate words in common. So, for the purposes here, Landauer and his colleagues have presented convincing evidence that, in fact, the scope of vocabulary acquisition can be both an inductive and experience-based process that is grounded on a set of foundational underlying semantic dimensions, a view that is contrary to that of many linguistic theorists and traditional researchers in vocabulary development (see Landauer, 2002). 
A research-based strategy for inductively accelerating vocabulary acquisition of at-risk students

In offering a solution to the classical problem of how persons can know more than experience could have taught within the context of vocabulary, Landauer (2002) and Landauer and Dumas $(1997,1998)$ drew on the idea that the underlying semantic dimensions that represent the relatedness among words, phrases, and prose provide "learning leverage" through which words are known. As an example of the problem, Landauer reported that the daily rate of growth in reading vocabulary in middle school children per paragraph of reading is about 4 times the number of newly learned words that actually appear in the texts they read each day- a strong argument for an inductive process of vocabulary acquisition. Considered informally, the basis for such an inductive process is an underlying semantic framework that provides the means through which the meaning of new words is partially known and/or how the meaning of new words can be induced from the contexts within which they appears. As a simplified illustration, Landauer (2002) uses the example of how the meaning of a new word using LSA is established as the sum of the meanings of the words in which it is embedded. From this perspective, in the sense of Kintsch's model, learning the meaning of a new word is primarily a matter of accessing some function of existing prior knowledge (e.g., LSA semantic dimensions) rather than literally learning a new meaning. Thus, Landauer's argument is that the majority of vocabulary acquisition is a process through which an integration of prior semantic meaning provides the means for the inductive process of vocabulary learning that is logically necessary to explain the rate of vocabulary growth.

In fact, there is a pattern of other empirical support for Landauer's (2002) argument. First, it is consistent with traditional research emphasizing the learning of vocabulary through context (see Anderson \& Nagy, 1991). Again, the interpretation of this effect is that the underlying semantic dimensions of the set of words (e.g. cohesive paragraph) forming the context in which a new word is embedded provides the basis for the induction of word meaning. Second, Perfetti and Wlotko (2005) reported that a limited number of multiple contexts in which a word was presented (vs. a definition) were sufficient for the establishment of new vocabulary in experimental settings. Consistent with Landauer's argument, the semantic relatedness of the different groups of words provided an elaborated contextual focus for the "gist" of word meaning. Third, Vitale and Papay (1974) demonstrated that the semantic features of multiple groups of meaningful words could engender profiles of meaning for nonsense syllables that could subsequently be manipulated independently. Again, in this study, the new meaning of a nonsense syllable (i.e., word) was based upon the combination of the underlying prior semantic knowledge of the words in which it was "embedded", providing an experimental demonstration of how aspects of word meaning can evolve experientially. Fourth, a meta-analysis by Marmolejo (1990) found that the direct teaching of vocabulary using focused semantic-based techniques was more effective for poor readers than definitions or definitions in context (i.e., learning from reading alone). And, finally, a recent study (Romance \& Vitale, 2009) based on Kintsch's model (1994, 1998a, 1998b, 1998, 2002, 2005) has shown how a knowledge-focused reading comprehension strategy which guides students to access of prior knowledge when reading can enhance reading achievement. As an interpretative perspective, the knowledge-focused reading comprehension strategy used by Romance and Vitale provides a complementary framework for the multi-part instructional strategy used in the present study. Specifically, in addressing Landauer's (2002) argument regarding the dependence of prior knowledge as a key to the operational dynamics underlying vocabulary induction and gaining meaning from context, the strategy used by Romance and Vitale to engender student access of prior knowledge logically addressed the same learning/transfer mechanism required for indirect vocabulary learning.

\section{Conclusions}

Considered together, the traditional and cognitive science research literatures are consistent in that while vocabulary words can be taught directly, the majority of vocabulary is learned from context in an inductive fashion. Although some indirect learning can be explained through reading, explaining the rate of vocabulary acquisition requires the identification of a process that involves the induction of the meaning of new words (since direct teaching and incidental learning from reading contexts are inadequate to explain vocabulary growth). However, in combination with one another, the construction-integration model by Kintsch and the LSA model by Landauer provide a mechanism through which prior knowledge can provide the means for the 
induction of the meaning of new vocabulary words. Considered together, these interdisciplinary perspectives are suggestive of elements that could engender induction of new vocabulary words as an extension of direct teaching of a limited set of vocabulary words, an approach that promises to be effective for at-risk and non-at-risk student populations.

From a research standpoint, this study is potentially important in two ways. First, it integrates and applies complementary interdisciplinary findings from areas of investigation that are relevant to advancing the understanding of how to accelerate student vocabulary development, a recognized educational need. Thus, the findings are systemically relevant to K-12 schools because of their potential for raising the achievement expectations of at-risk elementary students in both vocabulary learning and in other related outcomes (e.g., reading comprehension). Second, the findings also have important implications for (a) establishing the feasibility of broadening the application from grade 4 across the K-5 grade range and beyond, (b) providing the means for building the capacity of schools to expand the intervention to new schools through the development of mentor teachers, and (c) exploring the effectiveness of strategies for establishing the "added value" the intervention offers schools in the form of the raised achievement expectations that provide the dynamics for systemic school reform.

At the same time, it is important that the results of the present study are replicated and extended, both in terms of length of instructional time (duration of study) and across grade levels (K through 5). In particular, such studies should assess the differential impact of such cumulative learning environments upon low-SES students, both in terms of vocabulary development and in terms of content-area reading comprehension. In conducting studies on vocabulary acquisition, the present study and the research cited in the literature review are suggestive that development and use of semantic meaning as represented by semantic word families should be the focus of vocabulary acquisition rather than simply learning the meaning of specific words in isolation. For practitioners, the results of the present study are suggestive of how student vocabulary acquisition and utilization can be accelerated through a systemic enhancement of their regular reading programs.

\section{References:}

American Federation of Teachers (AFT). (1997). Making standards matter, 1997: An annual fifty state report on efforts to raise academic standards. Washington, DC: AFT.

Anderson, R. C., \& Nagy, W. (1992). The vocabulary conundrum. American Educator, 16, 14-18, 44-47. <http://dx.doi.org/10.2307/3193321>

Anglin, J. M. (1993). Vocabulary development: A morphological analysis. Monographs of the Society for Research in Child Development Serial No. 238, 58(10), 118-152.

August, D., Carlo, M., Dressler, C., \& Snow, C. (2005). The critical role of vocabulary development for English language learners. The Division for Learning Disabilities of the Council for Exceptional Children, 20(1), 50-57.

Baker, S. K., Simmons, D. C., \& Kameenui, E. J. (1998). Vocabulary acquisition: Research bases. In D. C. Simmons and E. J. Kameenui (Eds.), What reading research tells us about children with diverse learning needs (pp. 183-218). Mahwah, NJ: Erlbaum.

Baumann, J. F., \& Kameenui, E. J. (1991). Research on vocabulary: Ode to Voltaire. In J. Flood, J. Jensen D. Lapp, \& J. Squire (Eds.), Handbook of research on teaching the English language arts (pp. 604-632). NY: Macmillan.

Beck, I., \& McKeown, M. (1991). Conditions of vocabulary acquisition. In R. Barr, M. Kamil, P. Mosenthal, \& P. D. Pearson (Eds.), Handbook of reading research (Vol. 2) (pp. 789-814). White Plains, NY: Longman.

Beck, I., Perfetti, C., \& McKeown, M. (1982). Effects of long-term vocabulary instruction on lexical access and reading comprehension. Journal of Educational Psychology, 74, 506-521. <http://dx.doi.org/10.1037/0022-0663.74.4.506>

Becker, W. C. (1977). Teaching reading and language to the disadvantaged - What we have learned from field research. Harvard Educational Review, 47, 518-543. 
A research-based strategy for inductively accelerating vocabulary acquisition of at-risk students

Biemiller, A., \& Boote, C. (2006). An effective model for building meaning vocabulary in primary grades. Journal of Educational Psychology, 98(1), 44-62. <http://dx.doi.org/10.1037/0022-0663.98.1.44>

Biemiller, A., \& Slonim, N. (2001). Estimating root word vocabulary growth in normative and advantaged populations: Evidence for a common sequence of vocabulary acquisition. Journal of Educational Psychology, 93(3), 498-520.< http://dx.doi.org/10.1037/0022-0663.93.3.498>

Blachowicz, C., \& Fisher, P. (2000). Vocabulary instruction. In M. L. Kamil, P. B. Mosenthal, P. D. Pearson, \& R. Barr (Eds.), Handbook of reading research (Vol. 3) (pp. 503-523). Mahwah, NJ: Erlbaum.

Boucher, C. R. (1986). Pragmatics: The meaning of verbal language in learning disabled and non-disabled boys. Learning Disability Quarterly, 9(4), 285-294. <http://dx.doi.org/10.2307/1510382>

Bransford, J. D., Brown, A. L., \& Cocking, R. R. (2000). How people learn. Washington, DC: National Academy Press.

Carver, R. (1994). Percentage of unknown vocabulary words in text as a function of the relative difficulty of the text: Implications for instruction. Journal of Reading Behavior, 26(4), 413-437.

Coyne, M. D., McCoach, D. B., \& Kapp, S. (2005). Teaching vocabulary to kindergarten students during shared storybook readings: A comparison of rich instruction, basic instruction, and incidental exposure. Paper presented to the USDOE Institute of Educational Sciences Reading Comprehension Principal Investigator Group Meeting, Washington, DC.

Donahue, P. L., Voek1, K. E., Campbell, J. R., \&Mazzeo, J. (1999). NAEP 1998 reading report card for the states. National Center for Educational Statistics, Office of Educational Research and Improvement. Washington, DC: U.S. Department of Education.

Feldman, S. (2000). Standards are working: But states and districts need to make some mid-course corrections. American Educator, 24(3), 5-7.

Graves, M. F. (1986). Vocabulary learning and instruction. In E. Z. Rothkopf (Ed.), Review of research in education (pp. 49-89). Washington: American Educational Research Association.

Hart, B., \& Risley, R. T. (1995). Meaningful differences in the everyday experience of young American children. Baltimore: Paul H. Brookes.

Johnson, C., \& Johnson, D. (2004). Wordly wise 3000. Cambridge, MA: Educators Publishing Service.

Johnson, G., Gersten, R., \& Carnine, D. (1987). Effects of instructional design variables on vocabulary acquisition of learning disabilities students: A study of computer-assisted instruction. Journal of Learning Disabilities, 20(4), 206-213. <http://dx.doi.org/10.1177/002221948702000402>

Kintsch, W. (1994). Text comprehension, memory, and learning. American Psychologist, 49(4), 294-303. <http://dx.doi.org/10.1037/0003-066X.49.4.294>

Kintsch, W. (1998a). Comprehension: A paradigm for cognition. Cambridge, United Kingdom: Cambridge University Press.

Kintsch, W. (1998b). The role of knowledge in discourse comprehension: a construction-integration model. Psychological Review, 95(2), 163-182. <http://dx.doi.org/10.1037/0033-295X.95.2.163>

Kintsch, W. (2002). On the notions of theme and topic in psychological process models of text comprehension. In M. Louwerse \& W. van Peer (Eds.), Thematics: Interdisciplinary Studies (pp. 157-170). Amsterdam, The Netherlands: John Benjamins Publishing.

Kintsch, W. (2004). The Construction-Integration model of text comprehension and its implications for instruction. In R. Ruddell \& N. Unrau (Eds.), Theoretical models and processes of reading (5th ed.) (pp. 1270-1328). Newmark, DE: International Reading Association.

Kintsch, W. (2005). An overview of top-down and bottom-up effects in comprehension: The CI Perspective. Discourse Processes, 39(2\&3), 125-128. <http://dx.doi.org/10.1080/0163853X.2005.9651676>

Landauer, T. K., \& Dumais, S. T. (1996). How come you know so much? From practical problem to theory. In D. Herrmann, C. McEnvoy, C. Hertzog, \& M. Johnson (Eds.), Basic and applied memory research: Theory in context (pp. 105-126). Mahwah, NJ: Erlbaum.

Landauer, T. K., \& Dumais, S. T. (1997). A solution to Plato's problem: The latent semantic analysis theory of the acquisition, induction, and representation of knowledge. Psychological Review, 104(2), 211-240. <http://dx.doi.org/10.1037/0033-295X.104.2.211> 
Vitale, M. R. \& Romance, N. R.

Landauer, T. K., (2002). On the computational basis of learning and cognition: Arguments from LSA. Psychology of Learning and Motivation, 41, 43-84.

Landauer, T. K., Foltz, P. W., \& Laham, D. (1998). An introduction to latent semantic analysis. Discourse Processes, 25, 259-284. <http://dx.doi.org/10.1080/01638539809545028>

Luger, G. F. (2008). Artificial intelligence: Structures and strategies for complex problem solving (5th ed.). Addison Wesley.

Marmolejo, A. (1990). The effects of vocabulary instruction with poor readers: A meta-analysis. Unpublished Doctoral Dissertation, Teachers College: Columbia University

McKeown, M. G., \& Beck, I. L. (2003). Taking advantage of read alouds to help children make sense of decontextualized language. In A. van Kleeck, S. A. Stahl, and E. B. Bauer (Eds.), Storybook reading (pp.159-176). Mahwah, NJ: Erlbaum.

Nagy, W., \& Anderson, R. C. (1984). How many words are there printed school English? Reading Research Quarterly, 19, 304-330. <http://dx.doi.org/10.2307/747823>

Nagy, W., \& Scott, J. A. (2000). Vocabulary processes. In M. L. Kamil, P. B. Mosenthal, P. D. Pearson, \& R. Barr (Eds.), Handbook of reading research (Vol. 3) (pp. 269-284). NY: Routledge.

National Research Council (1998). Preventing reading difficulties in young children. Washington, DC: National Academy Press.

Paul, P. V., \& O’Rourke, J. P. (1988). Multimeaning words and reading comprehension: Implications for special education students. Remedial and Special Education, 9(3), 42-52. $<$ http://dx.doi.org/10.1177/074193258800900308>

Perfetti, C. A., \& Wlotko, E. (2005). Learning the meaning of words. Paper presented at the Annual Meeting of the American Educational Research Association, Montreal, Canada.

Romance, N. R., \& Vitale, M. R. (2009). Transfer effects of a reading comprehension strategy on achievement and teacher judgments across grades 3-7. Paper presented at the Annual Meeting of the American Educational Research Association, San Diego, CA.

Snow, C. E. (2002). Reading for understanding. Toward an R\&D program in reading comprehension. Santa Monica, CA: RAND.

Stahl, S. A., \& Sheil, T. G. (1999). Teaching meaning vocabulary: Productive approaches for poor readers. In Read all about it! Readings to inform the profession (pp. 291-321). Sacramento: California State Board of Education.

Vitale, M. R., \& Papay, J. P. (1974). Conditioning a multidimensional meaning response. Catalog of Selected Documents in Psychology, 4, 71.

Vitale, M. R., \& Romance, N. R. (2007). A knowledge-based framework for unifying content-area reading comprehension and reading comprehension strategies. In D. McNamara (Ed.), Reading comprehension strategies: Theory, interventions, and technologies (pp. 73-104). Mahwah, NJ: Lawrence Erlbaum.

Wagner, R. (2005). Causal relations between the development of vocabulary and reading comprehension. Paper presented at the Annual Meeting of the American Educational Research Association, Montreal, Canada.

White, T. G., Graves, M. F., \& Slater, W. H. (1990). Growth of reading vocabulary in diverse elementary schools: Decoding and word meaning. Journal of Educational Psychology, 82(3), 281-290. <http://dx.doi.org/10.1037/0022-0663.82.2.281>

Zeno, S. M., Ivens, S. H., Millard, R. T., \& Duvvuri, R. (1995). The educator's word frequency guide. Brewster, NY: Touchstone Applied Science Associates. 